\author{
Etuk, I. S \\ Ikpeme $\mathbf{O}$. \\ Essiet G. A.
}

\section{Nocturnal Enuresis And Its Treatment Among Primary School Children In Calabar Nigeria.}

Received: 10 February 2011

Accepted: 23 May 2011

\section{S. Etuk $(\varangle)$, O. Ikpeme \\ Department of Paediatrics College Of Medical Sciences University Of Calabar Calabar Email: \\ Etukimaobong@Yahoo.Com.}

\section{G. A. Essiet}

Department Of Pharmacology College Of Medical Sciences University Of Calabar Calabar.

\begin{abstract}
Background: Enuresis for most children is a source of shame and anxiety with a profound effect on self perception, relationship and school performance. Hence the study of nocturnal enuresis among primary school children in CalabarNigeria.
\end{abstract}

Objectives: This was to determine the frequency of enuresis among primary school children in Calabar and to study the treatment modalities.

Patients And Methods: This was a prospective cross sectional study. A questionnaire was answered by parents of 3,230 pupils from six selected schools during the school term between January to March, 2010.

Results: The frequency of nocturnal enuresis was $6.7 \%$. Enuresis frequency was higher among boys (7.3\%) than girls
$(6.0 \%)$ though this was not statistically significant $(\mathrm{P}=0.216)$. Treatment methods used were medication $(1.6 \%)$, water restriction $(42.8 \%)$, awaking for voiding $(27.3 \%)$ use of alarm bell $(0.5 \%)$, herbal medication $(8.0 \%)$, while $19.8 \%$ received no form of treatment. Help seeking behavior for this condition was poor as only $2.1 \%$ of this study population ever sought medical attention for this condition.

Conclusion: The frequency of enuresis was similar to most reports in literature. Help-seeking behavior was poor. Parental education, advocacy and awareness creation on the availability of medical help for enuresis are suggested.

Key words: Nocturnal enuresis, Treatment, School children.

\section{Introduction}

Nocturnal enuresis, an involuntary voiding of urine during sleep in the absence of congenital and acquired defects of the central nervous system or urinary tract in a child aged 5 years and above, is a major source of anxiety to the family. ${ }^{1}$ It is also a source of shame and embarrassment. That it causes profound loss of self- esteem, self-perception and poor inter-personal relationship which may affect the quality of life and school performance has been reported. ${ }^{1-4}$ Hence the goal of treatment of this condition is to reduce its social and psychological impact and possibly eliminate the cause. ${ }^{2,3,5,6}$. In spite of this, less than 30 percent of parents of enuretics seek medical attention for this social and behavioural changing problem, particularly in the developing countries. ${ }^{4,6}$

The prevalence and treatment modalities for enuresis have been studied variedly in different parts of the world including Africa. This seems to vary with age and from country to country. Paucity of information continues to exist on this subject in this part of the world. The present study therefore aims at determining the frequency, the help-seeking behaviour of parents and types of treatment offered to enuretic children in Calabar. 


\section{Subjects and methods}

This was a descriptive, cross sectional, prospective study carried out between January and March 2010 among primary school children in Calabar Nigeria. Calabar is the capital of Cross River State in the South South geopolitical zone of Nigeria. It has an estimated population of 375,196 (report of 2006 National census). The inhabitants are mainly the Efiks, Quas, Ejagham, Efut, Ibibio, Annang and others the migrant workers. They are mainly civil servants, subsistence farmers, traders and fishermen.

A multi-stage random sampling method was adopted as a means of selecting the schools and pupils for the study.

A list of all public and private nursery / primary schools in Calabar was obtained from the Ministry of Education, Cross River State. This was arranged alphabetically; a table of random numbers was used to select schools and pupils that would make up the sample size.

According to the estimated prevalence of enuresis and population size; a sample size of 3,223 with $95 \%$ confidence level was required.

Based on this a total of 3 public and 3 private schools were selected. The pupils aged $612 \mathrm{yrs}$ in these schools formed the study population.

Before commencement of the survey, approval was obtained from Cross River State Primary Education School Board. In the schools, the head and class teachers were briefed on the purpose of the study and on the questionnaire.

Following this, 3,230 questionnaires on enuresis were given out to the children who were aged between 6-12 years in the six schools. These were filled in by the parents at home and retuned by the pupil the following day. The class teachers were instructed to help clarify issues with the parents on some questions where necessary.

Each parent was to indicate whether his/her child had suffered from nocturnal enuresis in the previous 6 months and if so, the kind of treatment that was offered either at home or in hospital.

For the purpose of this study, the following definitions were made.
Primary nocturnal enuresis was defined as bedwetting at least once a week in a child who has not had night-time bladder control for 6 months or more. ${ }^{7}$

Secondary enuresis and diurnal enuresis without nocturnal enuresis were excluded from the study.

Treatment were categorized as enuresis alarm, medication, water restriction, awaking for voiding, use of herbal medication and untreated based on literature review. Those who have visited the hospital for this condition were also noted.

The data obtained was presented as tables and chisquared test was calculated using EPI info version 6.046 to test for frequency differences between the two sexes.

A level of $\mathrm{P}<0.05$ was considered statistically significant.

\section{Results}

Three thousand, two hundred and thirty $(3,230)$ questionnaires were administered and two thousand, seven hundred and eighty $(2,780)$ of them were correctly filled and retrieved. This gives a retrieval rate of $86.1 \%$ and formed the basis of this analysis. Of the 2,780 respondents, 1,536 were males and 1,244 were female giving a male to female ratio of 1.2:1. One hundred and eighty seven children were reported by parents as having nocturnal enuresis giving a prevalence rate of $6.7 \%$. The frequency of enuresis was higher in boys 112 (7.3\%) than girls $75(6.0 \%)$ but this difference was not statistically significant $\mathrm{X}^{2}=1.53, \mathrm{P}=0.216$. (Table 1)

The treatment methods are as shown in table 2. One hundred and fifty $(80.2 \%)$ of the children with enuresis received some form of treatment but only 4 $(2.1 \%)$ ever consulted doctors by way of seeking help for their children's condition. Only one child $(0.5 \%)$ was using alarm bell. Drug medication was used by $1.6 \%$ of the subjects. Water restriction, awaking for voiding, and herbal treatment was used by $42.8 \%, 27.3 \%$ and $8.0 \%$ of the subjects respectively. About Twenty percent of the patients received no form of treatment for their condition.

Table 1

Distribution of population and frequency of nocturnal enuresis by

\begin{tabular}{lcccccc}
\hline Sex & Population no & Sample size no & Enuresis cases no & Enuresis frequency (\%) \\
\hline Female 6,094 & 1,24475 & & 6.0 & & & \\
Male 8,857 & & 1,536 & & 112 & 7.3 & 6.7 \\
Total & 14,951 & & & 2,780 & 187 & 6.7 \\
\hline
\end{tabular}

$$
X^{2}=1.53 \quad p=0-216
$$


Table: 2

Methods of treatment of nocturnal enuresis in 187 Children in calabar

\begin{tabular}{lll}
\hline Treatment & No & $\%$ \\
Medication & 3 & 1.6 \\
\hline Water restriction & 80 & 42.8 \\
Awaking for voiding & 51 & 27.3 \\
Use of alarm bell & 1 & 0.5 \\
Herbal treatment & 15 & 8.0 \\
No treatment & 37 & 19.8 \\
\hline Total & 187 & 100
\end{tabular}

\section{Discussion}

Enuresis is a common world-wide medical and psychological problem among school age children ${ }^{8,9}$. In our study the overall prevalence of nocturnal enuresis was $6.7 \%$. This is similar to the rate reported by some authors ${ }^{4,10,11}$ and at variance to others ${ }^{12,13}$.

The prevalence of reported nocturnal enuresis depends on its definition. In this study, primary school children with bed wetting at least once a week were included. A near similar prevalence rate of $7.7 \%$ was obtained in a study in the Republic of Iran as this same definition was applied. ${ }^{11}$ In a study in UK an overall prevalence rate of $18.9 \%$ was recorded but reduced to $5.1 \%$ when the inclusion criteria were weekly incidences?

Demography reports from Sweden ${ }^{10}$ displayed nocturnal enuresis prevalence rates of $5-10 \%$ involving mostly boys. In Saudi Arabia enuresis prevalence rate of $15 \%$ was reported in children ${ }^{13}$ between 6-12 years. ${ }^{13}$ In Nigeria, Famuyiwa ${ }^{13}$ noted a rate of $25 \%$ of primary nocturnal enuresis among primary school children in Lagos. The definitions used in these studies with high prevalence rates were enuresis of at least once a month. If the definition was further fine tuned, the high prevalence rate would likely reduce, similar to the finding in the UK study. ${ }^{7}$

A questionnaire survey in the United Arab emirate ${ }^{12}$ recorded a prevalence of 5.5\% among 6-12 years old which is lower than what the current study showed. The proportion of younger children in their sample was small as against the present study. Another observation is that most of the studies with high rates used interviews instead of questionnaires methods. Parents may place less emphasis on the problem when questionnaires methods are used.

The prevalence of enuresis in this study was higher in boys $7.3 \%$ than in girls $6.0 \%$. However this was not statistically significant $(p=0.216)$. Most of the studies show higher enuresis rates in males than females ${ }^{7,10-13}$. However, spontaneous remission rate was found to be higher in girls. ${ }^{5,9}$

The present study showed that small percentage $(0.5 \%)$ of the subjects used enuresis alarm as a mode of treatment. Alarm treatment is the most successful treatment for bed wetting up to now, with initial and long-term success rates of $70 \%-90 \%$ and $50-70 \%$ respectively ${ }^{14}$, but unfortunately they are not available in our environment.

Children successfully treated with an enuresis alarm are less likely to relapse compared with those treated with pharmacological intervention. It is recognized in UK as the only therapy capable of effecting a long term "cure" to enuresis 6,14

About $20 \%$ of the subjects in the present study never received any form of therapy for their condition and only $4(2.1 \%)$ of the parents sought the services of a medical doctor. This is in contrast to the findings in most studies in the Western world, ${ }^{7,10-12}$ where as high as $90 \%$ of families seek medical help for their enuretic children, probably suggesting a low level of concern among parents in this city.

In Turkish families, only $19.8 \%$ of enuretic children use medical treatment ${ }^{7}$. Parents there rather prefer to wait for spontaneous recovery or use traditional methods of treatment. In Australia, ${ }^{15} 34 \%$ of families seek professional help and in Pakistan ${ }^{16} 26 \%$ while about $20 \%$ used traditional methods. In the present study $8.0 \%$ sought traditional treatment in form of herbs while majority employed mainly behavioural intervention.

\section{Conclusion}

The frequency of enuresis among primary school children in Calabar, Nigeria is similar to that reported in literature within and outside the country.

The frequency of overall medical help-seeking behaviour is low compared to other reports, suggesting a low level of concern among parents in Calabar. The use rate of enuresis alarm is very low. This calls for parental education, advocacy and awareness creation on the availability of medical help for enuretic children. Further research is needed into the methods of promoting effective and quality enuresis treatment.

\section{Acknowledgment}

We would like to thank Madam Edak O. Asuquo the Executive Secretary Cross River State Education authority who gave approval for the schools to be used for this study. Our appreciation also go to all the head and class teachers of the schools studied who patiently assisted in all stages of the study. 


\section{References}

1. Arvin A. M. Enuresis In: 6. Anochie I. Enuresis. $\mathbf{N i g} \mathbf{J ~ C l}$ Behrman RE, Kliegmna R M, Pract2003;6(2): 111114.

Eds Nelson's textbook of 7. Unalack M et al. Enuresis Pediatrics. London. W B. nocturnal Prevalence and risk Saunders co ( publishers) factors among school age $2004 ; 2077-9$

2. Landgraf J. M. Coping, Commitment, and attitude: quantifying the everyday 8 burden of enuresis on children and their families. Pediatrics 2004; 113:340 4 .

3. Schober J M . The Impact of 9. Mono symptomatic nocturnal enuresis on attachment parameters. Scand J Urol Nephrol 2002 38: 4752.

4. Thiedke C. Nocturnal enuresis. 10. Am f phys 2003; 67 (7): 1499 506.

5. Meadow SR. Enuresis. In CM Edelman, Eds Paediatric Kidney disease $2^{\text {nd }}$ edition. United States of America: Little, Brown and Company. 2001;2015 21.
11. $\quad \mathrm{P}$ a s h a o $\mathrm{ur} \mathrm{N}$, Golmahammadlou S, Mahmoodzahel H, Nocturnal enuresis and its treatment among primary school children in Oromiel, Islamic Republic of Iran. E Mediterr Hlth J2008; 14(2): 376380

12 .Eapen V. Mabrouk A M. Prevalence and correlates of nocturnal enuresis in the United Arab Emirates. Saudi MedJ2003;24(1): 4951.

13. Famuyiwa O. O. Enuresis. Nig Med Pract 2001 10:97-102.

14. Leerdam F J. Alarm treatment is successful in children with day and night time wetting. Scand J Urol Nephrol_2004; 38 : 2115.

15. Cadwel ph. Bed wetting and toilet training problems in children. Med J Austr 2005, 182 (4): 190-2.

16. Mithanis S, Zaidi. Bed wetting in School children of Karachi. $J$ Pakistan Med Ass 200555 (1) : 2-5 